NATALIA NIKOLOVA, STEWART CLEGG, STEPHEN FOX, KJERSTI BJØRKENG AND

TYRONE PITSIS

\title{
Uncertainty Reduction through Everyday Performative Language Work:
}

\section{The case of coaching}

Accepted for publication in Int. Studies of Mgt. \& Org., vol. 43, no. 3, Fall 2013, pp. 74-90.

\begin{abstract}
In this study we focus on coaching in the context of small and medium enterprises in the creative industries. We draw on data collected from five business coaching organizations over numerous coaching encounters with their clients. Using detailed conversational data drawn from these coaching encounters we analyze the ways in which business coaches practice 'active listening' and 'reflective questioning' in order to reduce the uncertainties they and their clients face when working together. We show that they do so through the strategy of positioning 'performance' as central to their practice. Successful performances depend on the ability to convince clients that one's performance is what it represents itself as being, a performance that is brought off by detailed everyday language work, mimicking the client's language back on to the client. As such, coaches demonstrate themselves to be skilled analysts of everyday life and listening.
\end{abstract}

Natalia Nikolova is a Senior Lecturer at University of Technology Sydney Business School, PO Box 123 Broadway, NSW 2007 Australia, Tel.: +61 2 9514 3645, Fax: +61 2 9514 3602, E-Mail: natalia.nikolova@uts.edu.au; Stewart Clegg is a Professor at University of Technology Sydney Business 1 
School, PO Box 123 Broadway, NSW 2007 Australia, Tel.: +61 29514 3934, Fax: +61 29514 3312, E-Mail: stewart.clegg@uts.edu.au; Stephen Fox is a Professor at University of Technology Sydney Business School, PO Box 123 Broadway, NSW 2007 Australia, Tel.: +61 29514 3060, Fax: +61 29514 3602, E-Mail: steven.fox@uts.edu.au; Kjersti Bjørkeng is a Senior Researcher at SINTEF Technology and Society, 7465 Trondheim, Norway, Tel: 47-93087717, E-mail: kjersti.bjorkeng@sintef.no; Tyrone Pitsis is a Reader at Newcastle University Business School, Newcastle University, 5 Barrack Road, Newcastle Upon Tyne, NE1 4SE, United Kingdom, Tel.: +44 1919208 171, E-mail: tyrone.pitsis@ncl.ac.uk. 


\section{Introduction}

In the literature on consulting, the inherent uncertainty and ambiguity of consulting services is well documented (Clark 1995; Gallouj 1997; Glückler and Armbrüster 2003). Consulting services are characterized by behavioral and performance uncertainty associated with the confidential, intangible and interdependent nature of consulting knowledge (Alvesson 1993, Alvesson 2001; Clark 1995) and by institutional uncertainty framed by the lack of legitimated and enforceable professional standards in the consulting market (Glückler and Armbrüster 2003; McKenna 2006). These characteristics of consulting services have implications for the uncertainties faced by consultants and their clients. On the one hand, consultants are under constant pressure to create, legitimize, and sustain the practical value of their knowledge claims, especially given the increasing pressures they face from demanding clients (Sturdy 1997) with considerable economic power (Alvesson and Johansson 2002; Armbrüster 2006; Werr and Styhre 2003). On the other hand, these uncertainties have an impact on clients' ability to judge the quality of consultants' work that makes it difficult for clients to choose the 'right' advisor (Glückler and Armbrüster 2003) and to demonstrate the rationality of this choice (Bäcklund and Werr 2008). In addition, the ambiguity of the client's problem, i.e. when both parties do not really know what problem the client has or how to solve it, creates further uncertainty in the interaction between clients and consultants (Furusten 2009). Last but not least, the client-consultant relationship is embedded in an environment characterized by general management uncertainties, which increases the uncertainty in the interaction between clients and consultants (Sturdy 1997). As Fincham (2002-3, 68) argues, "the consultant role is seen as reproducing in heightened form the uncertainties of managerial work.” 
Critical perspectives on consulting argue that consultants manage the uncertainties inherent in their knowledge base and the relationship with the client by impression management and the use of rhetorical strategies (e.g., Alvesson 1993; Alvesson 2001; Clark 1995; Clark and Salaman 1998a, Clark and Salaman 1996b; Kieser 1997, Kieser 2002). Accordingly, management consultancies are not so much characterized by authoritative professional knowledge as by a 'degree of elaboration of the language through which one describes oneself and one's organization, regulates client orientations and engages in identity work’ (Alvesson 2001, 871). Consultants' "subjective orientations and person-bound talents ... are more significant than formal knowledge" (Alvesson 1993, 1005). Moreover, consultants seek to position their practice as the embodiment of an organized 'system of persuasion' (Alvesson 1993, 1011) through the presentation of self (Goffman 1973). The conclusion is that consultants manage and strive to reduce the uncertainty they face by virtue of power positioning vis-a-vis clients based on their elaborated rhetorical skills and strategies.

If a central problem for consultants is the presentation of self and their knowledge base as esoterically expert, business coaches have an even more problematic relation to manage. Their contention is that the client already knows their business as well as anyone but that they do not know all that they know: the job of the coach is to help them come to an awareness of this tacit knowledge by aiding enhanced insight. Not surprisingly, given this privileging of lay knowledge, albeit held tacitly, one of the most salient features of how coaches describe themselves is "a sense of insecurity in relation to how others (especially potential clients) understood their identity" (Clegg et al. 2007, 501). Coaches explicitly seek to position themselves as differing from consultants whom they characterize as offering standardized solutions (Clegg et al. 2007). Some coaches do this by combining business planning with 
facilitation techniques similar to those used in psychotherapy (e.g., de Haan et al. 2011; Segers et al. 2011) while others draw on process consulting (Schein 1969; 1999) and social learning approaches to consulting (Nikolova et al. 2009; McGivern 1983; Schein 1999; 2002; Schön 1983). In both cases, coaches’ main point of differentiation from expert consultants is their role as helpers who are there to facilitate clients' unlocking of hidden business potential (Pitsis 2008; Schein 1999) rather than to offer 'expert' solutions to clients' problems.

Business coaches also differentiate themselves from other forms of coaching (e.g. lifecoaching and executive coaching which are person specific) through focusing on skill development required to achieve business outcomes rather than on the personal or career goals of the person being coached. Business coaching also differs from traditional training in that it is process rather than curriculum or content based; it occurs through work, with methods of learning informally focused within the workplace and diffusely embedded in realtime practices (McCarthy 2010). The difference is between life and business coaching is that in the latter it is not the person per se but the business that is the object of therapy.

The coaching process typically involves the coach working with individuals one-to-one, or with small groups, to diagnose the current business situation, elaborate on future goals, identify internal and external resources, and assess and plan for the process of achieving those goals (Brown and Grant 2010; Grant, 2011; King and Eaton 1999; Porter 2000). Typically, coaching is non-directive; it focuses on skilful questioning designed to help business managers frame their solutions (Hill 1998). Business coaches establish collaborative partnership with their clients, emphasizing a balanced relationship and seeking to 'demystify' expertise (McGivern and Fineman 1983), working jointly with the client to help them achieve their goals (Storey 2003). Therefore, the term 'coaching' is used to focus activities on 5 
processes of 'empowering', 'developing', ‘supporting' and 'removing obstacles' rather than on being prescriptive, directive, or oriented to definite courses of action, as is more characteristic of mainstream consulting practice (Ellinger and Bolstrom 2002).

While the critical literature on consulting emphasizes that consultants manage their own and clients' uncertainties through impression management and rhetorical skills (e.g., Alvesson 1993; Alvesson 2001; Clark 1995; Clark and Salaman 1998a, Clark and Salaman 1996b; Kieser 1997, Kieser 2002), it is not clear whether these are equally important in client-coach interactions in which the client, not the coach is seen as an expert, and the coach is only there to help the client become aware of their knowledge. It is the aim of this study to provide empirically grounded insights into the practices of uncertainty reduction used by coaches. Our study builds upon existing research on process consulting (Schein 1969; 1999) and social learning approaches to consulting (McGivern 1983; Schein 1999; 2002; Schön 1983) that see coaching as reflective inquiry into the causes of clients’ problems (Blake and Mouton 1989; Czerniawska 2003), accessed through 'reflective conversation’ (Schön 1983, 130). While listening and responding with reflective questioning embedded in the clientspecific context have been presented as important problem-solving practices (Blake and Mouton 1989; McGivern and Fineman 1983; Schön 1987), we argue that these practices serve both problem solving and uncertainty reduction. Careful analytic attention to what coaches do when they coach enables the empirical address of these practices. The role of language is particularly important because the work of coaching is largely a discursive and conversational form of work, and our exploration of coaching is done through studying interactional and conversational practices. 


\section{Method}

The study reports explicitly on an advisory service initiated by the Australian Federal government to support small and medium-sized enterprises in the creative industries, although it is embedded in a larger study that we also draw on to frame the analysis. The government scheme offered free coaching services to companies that qualified, based on a range of economic metrics. Coaches were selected based on their former experience in the relevant industry sector and they had freedom to choose their forms of practice and type of client interaction. The coaches recorded coaching conversations; they were supplied with recording devices, which they used with the permission of those being coached in their actual coaching sessions in the organizations in question. All participants were provided with detailed information about the aims of the research projects. This information included the coaches explaining that they were collecting information, and partaking in a research study on the effectiveness of coaching. Both the coaches and coachees agreed to have sessions recorded for research purposes, and were required to sign a consent form that also indicated that the results of the study would be published. The average number of meetings per client was five and the average duration around an hour and forty minutes. We arranged transcription of the coaching sessions and analyzed the transcripts as well as original recordings, which provided a way to audibly 'observe' how coaches and coachees spoke with each other. Alvesson and Kärreman’s (2000) approach of discursive pragmatism, similar to conversation analysis (Llewellysn 2008; Sacks 1992; Silverman, 1998), provided the analytic frame.

Before recording coaching sessions, we collected and inspected documentary data found in-house and on the websites of the five coaching organizations in the overall study, 
which provided an initial understanding of how business coaches account for their approach to coaching work. We interviewed a total of eight coaches across the five coaching organizations about their work. We also interviewed a total of 18 of their clients and observed or recorded ten coaching sessions that totaled over 230 hours. When transcribed these audio recordings amounted to a transcription of 192,000 words. The material was initially coded and categorized in terms of coaching pedagogy and purpose, the procedures of the coaching session, the leading metaphors used by the coaches in everyday talk and in sessions, the learning ideology transmitted and the expected outcomes for clients from the coaching process. The focus was on the performative role of language in coaching interactions. We interpreted the coaches practices using the concepts of 'active listening' and 'reflective questioning' to account for how they construct the value of their practices, clarify the problems they are facing, and build trust and reduce clients' uncertainty through a process of discursive interaction.

We chose to focus on the concepts of 'active listening' and 'reflective questioning' because initial analysis of websites identified these as themes that were consistently stressed by business coaches. In workshops and seminars with business coaches in a prior project we had explored these concepts with coaches and had learnt that these were widely seen as the requisite skills (Clegg et al 2007); in addition, one business coaching firm had invited us to present our research, which we did in a simplified form. Using this opportunity as a focus group we further affirmed the importance of these concepts.

‘Active listening’, a concept originally introduced by Rogers and Farson (1957), denotes a process premised on a fundamental respect for the other, in which listening is a form of initial answering. To be an active listener entails comprehending, retaining and 
responding to the other (Oxford 1990). Active listening is thus "a relational discursive practice that enables community members to constitute mutual relationships and then to engage in a process of inter-subjective meaning generation” (Jacobs and Coghlan 2005, 133), quite distinct from giving advice (Rutter 2003).

'Reflective questioning' draws on two streams: learning by concomitantly doing and reflecting (Kolb 1984; Revans 1996) and learning by challenging mental models (Argyris and Schon 1996; Senge 1995). The central elements of such questioning were reflexivity and discovery (Sofo et al. 2010). Reflexivity was used to recognize and question set mental patterns; discovery created clearer articulation of problems and recognition of their complexity. We approached the coaches as engaged in what Weick (1995) calls sensemaking: we see coaches as practical ethnomethodologists, interrogating the grounds of mundane order and co-creating a new appreciation of the order they encounter (Garfinkel 1967; Weick 1995).

Using this frame, we concentrate on a particular set of coaching encounters between a coach and a client over a period of approximately two months each. The particular transcript excerpt analyzed below is chosen because it was representative of the data we analyzed and the coaching practices described can be found in all of the other cases. We chose not to describe these other cases in detail, as this would have made the article very complex.

Active listening and reflective questioning exposed

The following analysis is based on a typical small group focused coaching session, between Andrew, one of the coaches, and Paul and Catherine, entrepreneurs from a small creative industries organization, NEUNO. NEUNO is a small independent training college, which specialized in dance training for 'developing artists'. Government funds to NEUNO 9 
largely maintain its operation. Paul is the CEO of NEUNO and Catherine is a Marketing manager and a member of his management team. The data demonstrate practices of 'active listening' and 'reflective questioning'. These practices enable the coach and coachee to mitigate uncertainties by establishing a language that, as it takes its cues from the coachees, is shared, leading to an apparent common understanding of the main issues and the way forward.

Andrew began the session by locating it within the protocols of the advisory approach as specified by the government. The approach required coaches to fill out a business review template with information about client's industry, market, financials, human relations, operations and intellectual property.

\section{Excerpt 1}

Andrew: $\quad$ OK so we've got a couple of hours today, up to 4.30 if that's alright and what I'd like to do is talk broadly first about how the organization works and what it is that you do. Then I'd like to work through some parts of this report. This is the report template that I've filled out for you and to do some talk about the industry and the market, talk about your operations...

After some brief clarifications, Andrew moves to make a request:

\section{Excerpt 2}

Andrew: $\quad$ OK, so perhaps you can explain to me a little bit, in your own words about what that journey is for a developing artist. How they get to NEUNO and what they do when they're here?

Following this, the interview was then dominated by Paul for a long stretch explaining at length the workings of NEUNO to Andrew, who listens closely and interjects from time to time, asking questions of clarification, making remarks such as 'Right, sure. So when do the 10 
auditions take place' and sometimes offering a summary of an answer to double-check (a form of active listening) his understanding, for instance:

\section{Excerpt 3}

Andrew: $\quad$ OK, all right. So as a successful developing artist I rock up to NEUNO for orientation week, fill out - apply for Study grant, get all that kind of thing sorted out?

Paul: $\quad$ All that has to be done prior to you coming to NEUNO.

Andrew: $\quad$ Prior to coming to NEUNO?

Paul: $\quad$ Prior to coming to NEUNO. All the Study grant things, all has to be sorted out. All the travel, all the bookings has to be sorted out prior to that and we need information earlier too and they need to accept so then we can organize the accommodation scenarios.

Andrew: $\quad$ OK, no worries.

Paul: $\quad$ That's for the full time study.

Andrew: $\quad$ For the full time study?

Paul: $\quad$ Yeah, so before you rock up here at orientation week.

Andrew: $\quad$ How many people audition?

Paul: $\quad$ Anywhere between 30 and 40 we try to take but then we also have a bit of a drop off there because some people say that they're going to come and then they don’t come. Just don’t rock up. So that's a big shame, you know.

The conversation continued in this vein, with Paul mainly explaining and Andrew double-checking his understandings for 20 - 30 minutes, by which time Andrew begins to focus less on the day to day operations of the college and asks a set of questions about the 'board of directors,' the 'organizational structure,' its 'quality assurance,' and 'governing 11 
body’ and different methods for raising funds. He clarifies that Catherine is the marketing manager and plays a role in fund raising, that often they involve the 'artistic director' in strategic discussions, and put on shows that assist in fund-raising. They rapidly map out conversationally the different roles involved in the running of the organization from the Board to the marketing, the course director, artistic director, marketing manager, course administrator, someone to look after the accounts, bus driver, lawn mower, receptionist, cleaner, teachers, some of whom are casuals, others full time. Through this conversation Andrew establishes some common language and a map of basic elements of the organization as a foundation for the following (uncertain) value-based work with the client. Half way through the 1.5 hours, Andrew begins to ask questions that do not simply clarify the structure and personnel and what they each do but ask Paul to step back and reflect and begin to evaluate rather than describe and explain:

\section{Excerpt 4}

Andrew: $\quad$ OK, so that sounds pretty good. So, a few bigger picture ideas being developed through this person?

Paul: $\quad$ Yeah.

Andrew: $\quad$ Yeah. So is the staff structure appropriate, are you happy with it? Is it the right number of people in the right sort of places?

Paul: $\quad$ No.

Andrew: No?

Paul: $\quad$ It's a bit thin on the ground.

Andrew: $\quad$ Yeah? Where do you think - where's the thinness?

Paul: $\quad$ There's thinness in the Performing Arts Department. There's thinness in 
administration as well. I mean the issue of MFDE is pretty intense and to have that, to keep that up and running is pretty full on. Even though it depends on how many students you've got, you know, you still need a body of staff to do that.

It would be really interesting to make an - and I can just do this myself by ringing Jean and going: how many - what's the staff ratio at NATA?

Catherine: You could probably double the students without doing much to the staff, you know.

Paul: $\quad$ No, that's not true. You'd need huge ... from the Arts Department.

Catherine: Yeah.

Paul: $\quad$ Yes you would. The level of stuff they have to do is pretty full on.

Andrew: $\quad$ So it seems to me that performing arts and admin are two areas directly related to course delivery and that's where the thinness is?

Paul: $\quad$ Yeah.

Through this exchange, Andrew asks an evaluative question about whether the staff structure is appropriate, and Paul begins to express the problems he faces. Following this exchange Paul and Andrew begin to share the task of formulating the issues as well as beginning to explore an understanding of them, i.e. they begin to build agreement and hence certainty about the issues to be addressed. Through the questions and answers that follow they (a) search for possible articulation of the problems encountered, (b) search for possible sources of the problems, (c) offer possible solutions, and (d) negotiate which of them might do what to help resolve the problems in practice. Note several features about how the exchange in Excerpt 4 unfolds: early on, as soon as Paul indicates there is a problem, Andrew begins to reflect back to him his own words and phrases, in a way that identifies with Paul's 
account without ironing up or distancing himself:

Paul: $\quad$ No.

Andrew: No?

Paul: $\quad$ It's a bit thin on the ground.

Andrew: $\quad$ Yeah? Where do you think - where's the thinness?

In terms of turn taking in talk, Paul then answers this question about 'the thinness' with ‘There’s thinness in the Performing Arts Department. There’s thinness in administration as well.’ Before Andrew can reply, a short sequence of exchanges occurs between Paul and Catherine, which serve to test out the reality and extent of 'the problem' they face with the staff structure. Catherine's first interjection works to question Paul's claim that they are thin on the ground in staff; she suggests they could double student numbers without doing much to the staff. He counters that this is not true and adds details and she immediately backs down. He adds to his reasons. Straight after the Paul-Catherine exchange, Andrew sums up their answer to his question: ‘where’s the thinness?’ gaining Paul’s instant agreement, as follows:

Andrew: $\quad$ So it seems to me that performing arts and admin are two areas directly related to course delivery and that's where the thinness is?

Paul: $\quad$ Yeah.

Again, Andrew is building clarity and assurance in reinforcing the metaphor of 'thinness', which was originally Paul's. The whole sequence shows the coach picking up on Paul's language to define the problem in terms of thinness, thus simultaneously reducing Andrews's uncertainty of what this thinness might be, and Paul's uncertainty in his ability to 
identify and express the challenges of the organization. By playing it back the advisor is taking the phrase as meaningful but in a way that encourages further amplification of the meaning of thinness, which is then reinforced with the statement 'that's where the thinness is' at the end of the excerpt, having summarized two areas: performing arts and admin. Catherine does not interject again here nor does she do so for the several more exchanges between the two men that follow.

Andrew mirrors and reinforces the metaphor used by the senior client in defining his organization's problem with the staff structure. By adopting Paul's interpretation Andrew is ironing out the uncertainty associated with the disagreement between the two clients. When Catherine queries this definition of the problem, he does not ask her to amplify. He does observe the exchange between the two clients, in which Catherine questions Paul, Paul answers her and she backs down, and then he summarizes what Paul said were the two areas in which staffing was thin, and Paul agrees.

Andrew, using the same metaphor, then moves to another area, to explore whether 'thinness' might be a problem there too?

\section{Excerpt 5}

Andrew: The other kind of - the general running of the organization, the securing and maintaining the funding, the maintenance of the facilities, the marketing all those extra kind of things that's kind of under control? That's kind of - that's not where the thinness is?

Paul: $\quad$ It's getting better. We need a bit of a human resources person in administration to take care of that. At present I, myself and Carmella get bulked down in the day-to-day nitty-gritty of things. I mean the structure last year was that we had, I was called CEO and Head of Dance. Then we had a 
Chief Financial Officer and those two were equal. They weren’t equal when they took the job but when I came to the job the Board told me they were equal. Because they'd done a lot of politicking and things like that and that was hugely unsuccessful.

Andrew: $\quad$ Right, OK.

Paul: $\quad$ Hugely unsuccessful it was - he was not a very open sort of person.

Andrew: $\quad$ Yeah?

Paul: $\quad$ Philosophically he had no idea of the culture or teachers and it was just a nightmare. So that's when the board went through a consultation with an external consultant and then they came up with this structure as what it should be.

Andrew: $\quad$ OK, so this is a potential for new staff structure?

Paul: $\quad$ This is what we would like.

Andrew: $\quad$ This is what you would like? Brilliant, brilliant. Fantastic. So you moved from that kind of dual structure to a more hierarchical structure?

Paul: $\quad$ Yes.

Andrew: $\quad$ Yep, OK, cool. I think hierarchy sometimes gets a bad rap and I don't think it's a bad thing at all.

Paul: $\quad$ Yeah I think dual kind of works if you work really closely together and you're simpatico philosophical. I've worked in [unclear]. I was a dual person with most of my general managers. That worked really well.

In this sequence, Andrew works to reduce uncertainty both for himself and the coachees by testing out the extent of staffing thinness. In interaction with Paul he identifies a whole area of problems and their possible solutions. We see him inviting Paul to describe the other areas of the business of college management and say whether thinness of staffing is a 16 
problem there or not.

In Paul's long and winding explanation, it soon emerges that thinness as such is not a problem in this area but that the previous structure of last year was an issue because the CEO (himself) and the CFO were very different people. He mentions 'politicking' done by the Board, but that it was not successful. This causes Andrew to re-assess, which he does cautiously, by eliciting further clarification of the new issues inexplicable in terms of thinness. Andrew's comment 'Right, OK' is non-committal, inviting elaboration. Paul states that the structure they had last year was 'hugely unsuccessful' adding a comment about the CFO: 'he was not a very open sort of person', opening up the issue of organization structure and bringing back uncertainty regarding the issues discussed. Andrew's next 'Yeah?' invites further elaboration. Paul reveals that the Board has already used an external consultant to define a new staff structure. Andrew clarifies this in a rather guarded way: 'OK, so this is a potential for new staff structure?' and Paul's answer makes it clear that they already have a solution to the previous dual structure: 'This is what we would like.' Andrew repeats this: 'This is what you would like?’ and immediately becomes positive: 'Brilliant, brilliant. Fantastic. So you moved from that kind of dual structure to a more hierarchical structure?' Relationally, the work done here is to build further common ground between the way Paul and Andrew evaluate the changes that have already taken place. Another summary by Andrew, some exchanges later, follows:

\section{Excerpt 6}

Andrew: $\quad$ Are you looking at ways for the General Manager to be the more kind of nittygritty sort of person and for you to be the more leading kind of bigger picture kind of person? 
Paul: That's the goal. That's the goal but we've got to get there first. It's only been five months in this...

Andrew: $\quad$ Yeah, sure, in the new structure, yeah.

Paul: $\quad$ This will be the fifth month.

Catherine: Of course.

Paul: $\quad$ Yeah OK, all right.

Having identified the purpose of the changes and the timeframe, Andrew, quickly moves to locate the potential for further problems here:

\section{Excerpt 7}

Andrew: $\quad$ So what are the - recognizing that it's still very new, what's stopping you from moving those two positions in that way? What's bogging you down?

Catherine: $\quad$ Poor skills of the people...

Paul: Underneath us.

Catherine: $\quad$...underneath and the lack of manpower for them to be able to do their job.

Paul: $\quad$ Not that she's got an opinion on it

Catherine: No.

Through a sequence of moves in the excerpts examined, Andrew shifts the conversation from Paul talking broadly 'about how the organization works' and what it is that he does, to explaining what multiple people seek to do and the difficulties holding them back. In Excerpt 7, Paul and Catherine agree about the problems whereas in Excerpt 4 momentary disagreement occurs. All three now largely talk about the problems faced by the organization in a common language, using similar metaphors, representing an important shift from 
uncertainty to certainty in the way the coach and the clients talk about and interpret the issues and a shared view of the issues between Paul and Catherine.

Andrew builds a common metaphorical language on remarks initially elicited from the client and reflects it back through 'active listening' and 'reflective questioning' to establish a trusting relationship. Consistent with the data from the 18 coaching encounters followed, the clients seemed comfortable in the conversations, seeing value in the coaching. No clients criticized the value of coaching and all stressed the great value seen in the relationship with the coaches. Particularly valued were coaches' skills in making the client aware of their own knowledge and assisting the client in finding ways to address the issues they faced. Several clients referred to their coach as mentor, signaling the trust built during the coach-client interaction.

The detailed practice of the coaches was subtle and 'systematically unsystematic'. No standardized solutions were proffered to the client but an account of the problems faced was skillfully drawn out that were then fed back to the client in the form of a metaphorical language that latched on to the client's sense-making. Such was the systematic element. What was unsystematic was the inability to know in advance what the terms in use would be. Coaching practice grasps and enhances critical moments in which metaphorical sense can be made, using this as an interrogatory device to elicit solutions that reduce uncertainty.

Summarizing, we suggest that the coaches’ practice resides in a fine-grained attention to the particulars of client's everyday speech. Active listening, as it is present in the everyday practice of coaching, bears the mark of first, double-checking the understanding of facts presented, and second, encouraging suggestions of solutions that the coachee presents. Both of these modes of active listening are ways of minimizing the uncertainty of the coach as well 19 
as the coachee. The double-checking of facts simultaneously constructs the validity of the coachees' utterances and assures the coach of the validity of their interpretation reducing uncertainties in their interaction. By encouraging suggestions for solutions the coachee's selfconfidence is enhanced; simultaneously confidence grows in the coaches’ ability to enable the organizational course of action. Diminishing the uncertainty of the coachee has a simultaneous parallel effect for the coach and the coach’s role. Reflective questioning is recognized through first, mirroring of metaphors, and second, drilling into details. Mirroring metaphors creates an opening for a shared language as metaphors are given content by the coach drilling into the details of organizing reflected in these metaphors. Such reflective questioning diminishes uncertainty, as the coach and the coachee collaboratively construct a shared understanding of the organizational landscape in and through a language made common by the coach.

\section{Discussion}

Business coaching constitutes identity emphasizing practices of 'active listening' and 'reflective questioning' as core processes that not only highlight coaches' role as helpers differentiating the profession from 'traditional', expert consulting (see also Clegg et al. 2007) but also establish the value of its practice and contribute to the development of shared understanding and trust that reduces uncertainties for both coach and coachee. In contrast to the critical literature on consulting that stresses consultants' impression management and rhetoric as practices for managing consultants’ and clients’ uncertainties (e.g., Alvesson 1993; Alvesson 2001; Clark 1995; Clark and Salaman 1998a, Clark and Salaman 1996b; Kieser 1997, Kieser 2002), our study suggests that coaches performance situates the client as participant and co-creator through carefully reflecting the client's language back to the client 
creating trust and reducing uncertainty.

Practicing coaching is not primarily reflective but active, unfolding by responses to possibilities present, always potentially surprising, always dependent on and embedded in the gestures and responses made by clients. Active imagery unfolds simultaneously as a reflection of the particularities of practice and the inherent unpredictability of gestures and responses. With Czarniawska-Jorges (1996: 158) we suggest the centrality of 'performance' for practice as the means through which uncertainty is minimized. Successful performances depend on the ability to convince others that one's performance is what it represents itself as being, as authentically practice-related and productive. The performances constituted through practicing were hardly predictable; expert knowledge or tools as a part of the consulting stock-in-trade were eschewed as coaches’ constantly reflected back the coachees’ key metaphors, coalescing local proclivities, gestures, and responses. Coaching practice is thus a joint 'product' constructed by means of continuous negotiations with clients and the joint possibilities negotiated about what they do, can do, and wish to do. Creating a common interpretation of the problem reduces uncertainty associated with ambiguous client problems. Involving coachees in the 'production' of advice creates trust and reduces their uncertainty regarding the quality of the coach.

Coaching implies a strong emphasis on the relational bonds and psychological contracts constituting the client-coach relationship. The client is portrayed as being smarter than they think they are, as having the answer or solution to their own problem, but not realizing it. The coach's role is to be a muse, to listen and ask the 'right' questions, activating the processes of working through challenges and problems. Coaches create a safe space for clients to share views and emotions. Successful performances by the coach depend on detailed everyday 21 
language work and analysis of everyday life and listening. The coach’s ability to convince clients through carefully reflecting the client's language back to the client is a practice that situates and reproduces the client as participant and co-creator of the performance. Alvesson and Sveningsson (2003) suggest that mundane, everyday language acts carried out by someone labeled expert (i.e. a consultant, a coach, a manager) create an expectation of something significant being achieved: an impression of value is created by skillfully constructing mundane activities as extraordinary.

\section{Conclusion}

Coaches trade off the competencies of their coachees, using active listening and reflective questioning to do so, in order to surface solutions to problems that are posed. The important point is that the coach does not bring a solution to bear, does not provide an answer as such, but draws out a solution to the problems articulated by the coachee through careful and subtle questioning and responding. In some ways, successful coaches exemplify the analyses of the ethnomethodologist (Garfinkel 1967) into how social order is possible: they co-create a ceremonial order with their coachees that enables the taken for granted to become more evident than would otherwise be the case. From this process, solutions can be cocreated with the surety that any uncertainty that the coachee has is resolved by the legitimation provided by their ownership of their ideas. The key difference with consulting and its reduction of uncertainty is that the latter relies to a far greater extent on a context of expert knowledge and embedded expertise from which solutions can be proffered. The claims to expertise and its embeddedness in the knowledge management of the consulting company is a form of legitimation external to the process of consultation; by contrast, the business coaches carefully construct legitimation drawn from the fabric of the encounter itself. 


\section{References}

Alvesson, M. 1993. "Organizations as Rhetoric: Knowledge-Intensive Firms and the Struggle with Ambiguity." Journal of Management Studies 30(6): 997-1015.

Alvesson, M. 2001. "Knowledge Work: Ambiguity, Image and Identity." Human Relations 54(7): 863-886.

Alvesson, M., and A. Johansson. 2002. In Critical Consulting. New Perspectives on the Management Advice Industry, T. Clark and R. Fincham, eds., 228-46. Oxford: Blackwell Business.

Alvesson, M. and D. Kärreman. 2000. "Taking the Linguistic Turn in Organizational Research: Challenges, Responses, Consequences." Journal of Applied Behavioral Science 36(2): 136-158.

Alvesson, M. and S. Sveningsson. 2003. "Managers Doing Leadership: The ExtraOrdinarization of the Mundane." Human Relations 56(12): 1435-1459.

Armbrüster, T. 2006. The Economics and Sociology of Management Consulting. Cambridge: Cambridge University Press.

Bäcklund, J. and A. Werr. 2008. "Constructing the Legitimate Buyer of Management Consulting Services." Journal of Organizational Change Management 21(6): 758-772.

Blake, R. and J. Mouton. 1983. Consultation: A Handbook for Individual and Organizational Development. Reading, MA: Addison-Wesley.

Brown, S. W. and A. M. Grant. 2010. "From GROW to GROUP: Theoretical Issues and a Practical Model for Group Coaching in Organization." Coaching: An International 
Journal of Theory, Research and Practice 3(1): 30-45.

Clark, T. 1995. Managing Consultants. Consultancy as the Management of Impressions. Buckingham: Open University Press.

Clark, T. and G. Salaman. 1998. "Telling Tales: Management Gurus' Narratives and the Construction of Managerial Identity." Journal of Management Studies 35(2): 137-161.

Clark, T. and G. Salaman. 1996. In Organisation Development, Metaphorical Explorations, C. Oswick and D. Grant, eds., 154-74. London: Pitman Publishing.

Clegg, S. R. 1975. Power, Rule and Domination. London: Routledge.

Clegg, S. R., C. Rhodes and M. Kornberger. 2007. "Desperately Seeking Legitimacy: Organizational identity and emerging industries." Organization Studies 28(4): 495-513.

Czerniawska, F. 2003. Management Consultancy in the 21st Century. Houndmills: Macmillan Business.

Czarniawska-Joerges, B. 1996. In Understanding Management, S. Linstead, R. GraftonSmall, and P. Jeffcutt, eds. 151-71. London: Sage.

De Haan, E., V. Culpin and J. Curd. 2011. "Executive Coaching in Practice: What Determines Helpfulness for Clients of Coaching." Personnel Review 40(1): 24-44.

Ellinger, A.D. and R.P. Bolstrom. 2002. "An Examination of Managers’ Beliefs About Their Roles as Facilitators of Learning." Management Learning 33(2): 147-179.

Fincham, R. 2002-3. "The Agent’s Agent. Power, Knowledge and Uncertainty in Management Consultancy." International Studies of Management and Organization 
32(45): 67-86.

Fincham, R. 1999. "The Consultant-Client Relationship: Critical Perspectives on the Management of Organizational Change." Journal of Management Studies 36(3): 335351.

Furusten, S. 2009. "Management Consultants as Improvising Agents of Stability." Scandinavian Journal of Management 25(3): 264-274.

Gallouj, C. 1997. "Asymmetry of Information and the Service Relationship: Selection and Evaluation of the Service Provider." International Journal of Service Industry Management 8(1): 42-52.

Garfinkel, H. (1967) Studies in Ethnomethodology, Engelwood Cliffs, NJ: Prentice-Hall

Glückler, J. and T. Armbrüster. 2003. "Bridging Uncertainty in Management Consulting: The Mechanisms of Trust and Networked Reputation." Organization Studies 24(2): 269297.

Goffman, E. 1973. The Presentation of Self in Everyday Life. Edinburgh.

Grant, A. M. 2011. "Developing an Agenda for Teaching Coaching Psychology." International Coaching Psychology Review 6(1): 84-99.

Hill, P. 1998. "A School of Business Coaching." Training and Management Development Methods 12(4): 411- 415.

Jacobs C. and D. Coghlan. 2005. "Sounds from Silence: On Listening in Organizational Learning." Human Relations 58(1): 115-138. 
Kieser, A. 1997. "Rhetoric and Myth in Management Fashion". Organization 4(1): 49-74.

Kieser, A. 2002. In. Management Consulting. Emergence and Dynamics of a Knowledge Industry, L. Engwall and M. Kipping, eds., 167-83. Oxford: Oxford University Press.

King, P. and J. Eaton. 1999. "Coaching for Results." Industrial and Commercial Training 31(4): 145-150.

Kolb, D.A. 1984. Experiential Learning: Experience as the Source of Learning and Development. Englewood Cliffs, NJ: Prentice Hall.

Llewellyn, N. 2008. "Organization in Actual Episodes of Work: Harvey Sacks and Organizational Studies." Organization Studies 29(5): 763-791.

McCarthy, G. 2010. "Approaches to the Postgraduate Education of Business Coaches." Australian Journal of Adult Learning 50(2): 323-356.

McGivern, C. 1983. "Some Facets of the Relationship between Consultants and Clients in Organizations." Journal of Management Studies 20(3): 367-386.

McGivern, C. and S. Fineman. 1983. "Research and Consultancy: Towards a Conceptual Synthesis." Journal of Management Studies 20(4): 425-439.

McKenna, C.D. 2006. The World's Newest Profession: Management Consulting in the Twentieth Century. New York: Cambridge University Press.

Nikolova, N., M. Reihlen and J.F. Schlapfner. 2009. "Client and Consultant Interaction: Capturing Social Practices of Professional Service Production." Scandinavian Journal of Management 25(3): 289-98. 
Oxford, R., L. 1990. Language Learning Strategies: What Every Teacher Should Know. New York: Newbury House Publisher.

Pitsis, A. 2008. In The International Encyclopedia of Organization Studies, S. Clegg and J. Bailey, eds., 172-79. Thousand Oaks, CA: Sage.

Porter, S. 2000. "Building Business Success: A Case Study of Small Business Coaching." Industrial and Commercial Training 32(7): 241-245.

Revans, R.W. 1998. ABC of Action Learning. London: Lemos and Crane.

Rogers, C.R., and E.F. Richard. 1957. In Communication in Business Today, R.G. Newman, M.A. Danziger, and M. Cohen, eds. Washington, D.C.: Heath and Company.

Rutter, K.A. 2003. "From Measuring Clouds to Active Listening." Management Learning 34(4): 465-480.

Sacks, H. 1992. Lectures on Conversation. Oxford: Basil Blackwell.

Schein, E. 1987. Process Consultation. Lessons for Managers and Consultants. Reading, Mass.: Addison-Wesley Pub.

Schein, E. 1969. Process Consultation. Reading, Mass: Addison-Wesley Pub. Co.

Schein, E.H. 1999. Process Consultation Revisited. Reading, Mass.: Addison-Wesley.

Schein, E.H. 2002. In Critical consulting. New perspectives on the management advice industry, T. Clark and R. Fincham, eds., 21-27. Oxford: Blackwell Publishers.

Schön, D.A. 1983. The Reflective Practitioner: How Professionals Think in Action. New York: Basic Books.

27 
Schön, D.A. 1987. Educating the Reflective Practitioner. San Francisco: Jossey-Bass.

Segers, J., D. Vloeberghs and E. Henderickx. 2011. "Structuring and Understanding the Coaching Industry: The Coaching Cube." Academy of Management Learning \& Education 10(2): 204-221.

Silverman, D. 1998. Harvey Sacks: Social Science and Conversation Analysis. Cambridge: Polity.

Sofo, F., R.K. Yei and J. Villafañe. 2010. "Optimizing the Learning in Action Learning: Reflective Questions, Levels of Learning, and Coaching." Advances in Developing Human Resources 12(2): 205.

Storey, M. A. 2003. "Bringing head and heart to coaching." Organizational Development Journal 21(2): 77-81.

Sturdy, A. 1997. "The Consultancy Process-An Insecure Business?" Journal of Management Studies 34(3): 389-413.

Sturdy, A., K. Handley, T. Clark and R. Fincham. 2009. Management Consultancy, Boundaries and Knowledge in Action. Oxford: Oxford University Press.

Weick, K. E. 1995. Sensemaking, Thousand Oaks, CA: Sage.

Werr, A. and A. Styhre. 2002. "Management Consultants—Friend or Foe? International Studies of Management and Organization 32(4): 43-66. 